\title{
Las aristas y recorridos de la educación
}

DOI: https://doi.org/10.32870/dse.v0i12.270

\section{Antonio Ponce Rojo*}

Reseña del número 2 de la revista

Punto CuNorte. Revista académica del Centro Universitario del Norte. México: Universidad de Guadalajara/Centro Universitario del Norte, 2016.

El segundo número de la revista Punto CUNorte, intitulado "Educación: Aristas y recorridos", se compone de ocho artículos organizados en la revista de una manera equilibrada. Se trata de documentos cuidadosamente seleccionados, muy bien escritos y que dan cuenta de la calidad académica de esta nueva revista.

El primer artículo, escrito por Hugo Raymundo García Díaz, llamado "Formas expandidas de sociabilidad en los espacios escolares: mediatización de la experiencia escolar y uso del teléfono celular entre los estudiantes de secundaria", presenta los resultados de un estudio realizado en dos escuelas secundarias de Zapopan, Jalisco, en 2013, en el que se buscó analizar los usos que los alumnos de secundaria le dan al teléfono celular, pero dentro del mismo centro escolar. Da cuenta de la manera en la que los teléfonos celulares son usados por los adolescentes como soporte a la socialización y como un elemento mediador de la misma. El estudio realizó inicialmente observación en dos escuelas secundarias en Zapopan acerca de la manera en la que los adolescentes usan el teléfono celular. A la luz de las teorías que hablan de cómo los dispositivos móviles, es decir, los teléfonos celulares y las tablets, al igual que todas las tecnologías relacionadas con las comunicaciones en línea, unen a los que están lejos y separan a los que están cerca, fueron analizadas las prácticas en estas escuelas secundarias, encontrando justamente lo contrario. Aquí es donde descansa el principal aporte de este artículo y, por supuesto, del estudio del que éste da cuenta: los adolescentes no usan la telefonía celular como medio para aislarse o poner una barrera al entorno, sino como un medio para socializar. Generalmente, cuando uno ve que una persona tiene los audífonos puestos, se siente impedido para buscar establecer algún tipo de conversación con ella. De igual manera, se siente uno incómodo si ve que esta persona, una vez que hemos iniciado una conversación, no se quita los audífonos ni busca apagar el aparato al cual está conectado. El estudio en cuestión encontró que los adolescentes lo ven de una manera completamente distinta. Le dan otro

* Doctor en Ciencias del comportamiento. Profesor investigador del Departamento de Estudios en Educación de la Universidad de Guadalajara. Correo electrónico: aponcerojo@yahoo.com 
sentido al uso del celular y los audífonos. Usan un solo auricular de los audífonos, para estar escuchando música, al mismo tiempo que están conviviendo, conversando en incluso trabajando con los otros. Los adolescentes no se mostraron incomodados ante estas prácticas del otro, que platica con ellos mientras está escuchando música en su teléfono en un sólo auricular o incluso participan en pláticas en donde todos los involucrados, dos o más, escuchan música con un auricular, mientras platican con los demás.

Aquí está más clara que nunca esta habilidad identificada en las nuevas generaciones, las llamadas por Don Tapscott "generación punto net", para estar haciendo al mismo tiempo y de manera eficiente, más de una actividad, habilidad que, para las generaciones anteriores, nos suena completamente imposible. Asimismo, se observó también cómo los adolescentes, cuando no usan los audífonos, se reúnen a platicar mientras escuchan música en el altavoz de alguno de los teléfonos; comparten archivos por bluetooth (videos, fotografías, juegos, etc.). Con ello se da cuenta de la manera de estas nuevas prácticas de uso del teléfono celular como un medio para la expansión de la comunicación con los "otros" cercanos, ya que se da de manera paralela y sincrónica.

También se da cuenta en este artículo acerca de la manera en la que la producción propia de materiales para compartir con los amigos es una actividad a través de la cual se "está con los otros", al mismo tiempo en línea y de manera presencial.

En el segundo artículo, titulado "Actitudes hacia la matemática y su relación con el rendimiento académico mediante regresión logística", de Antonio Humberto Closas, Graciela Alicia Rohde, María Laura Estigarribia, Luciana Kuk e Idalia G. De Castro, se da cuenta de la manera en la que la actitud hacia las matemáticas se encontró relacionada estrechamente con el rendimiento académico medido a partir de las calificaciones de los alumnos participantes, en el sistema escolar argentino. Esta relación, además de ofrecer a los lectores pistas para hacer un análisis inverso, buscando aquellos elementos que resultan clave para poder explicar el éxito académico, nos ofrece los resultados de las acciones realizadas para poder contar con predictores del éxito o fracaso escolar, hecho que a la postre nos permitiría implementar acciones o diseñar las condiciones para asegurar el éxito académico. El aporte de este artículo descansa, creo yo, en el logro de un modelo empírico que aporta al campo de las explicaciones de esta compleja interrelación entre las actitudes hacia la educación, sus contenidos y las calificaciones finales de los alumnos. Asimismo, permite ver a las frecuentemente criticadas calificaciones desde otra óptica: como un medio efectivo finalmente para dar cuenta del conjunto ya no solamente de conocimientos, sino de actitudes de los alumnos hacia el conocimiento y hacia contenidos específicos en sus programas educativos.

El siguiente artículo es "El complejo conflicto de estar enredado: las redes de conocimientos y sus posibles significados", de Janette Alejandra González Hernández. Se trata un tema que presenta especial interés para mí, por abordar las redes de trabajo académico. La autora, quien desafortunadamente ha fallecido a finales del año pasado, planteaba en este documento la idea de un nuevo concepto en el ámbito de las redes de trabajo y colaboración académica: las redes de acción 
científica. Es una lástima, ya que la calidad del trabajo publicado en esta revista hace pensar en una carrera académica prometedora que desafortunadamente se vio truncada. En este documento, la autora hace una revisión de los diferentes enfoques teóricos que abordan a las redes, para partir de ahí hacia un análisis de las redes de trabajo académico y la necesidad de nuevos enfoques que den cuenta de las modalidades actuales que la generación de conocimientos impone: en donde ya no solamente intervienen investigadores y grupos de investigadores, sino instituciones, organizaciones, e incluso dispositivos como bases de datos o cualquier otro tipo de agentes: "las redes [dice la autora] favorecen a la comunicación entre expertos, ayudan a la formación de nuevos científicos, generan conocimiento, moldean la identidad de los investigadores y se expanden por territorios no explorados, ofreciendo nuevas modalidades de aprendizaje para los académicos..." La autora propone, como previamente he dicho, el concepto de redes de acción científica que son, en sus palabras, "configuraciones flexibles que vinculan a actores-individuos o actores-institucionales con el objetivo de crear, distribuir, transferir o aplicar conocimiento..."

Es una pena, repito, ya no poder discutir con la autora estos conceptos que dan cuenta de una mente brillante y dedicada a la generación de conocimientos sobre el propio proceso de generación de conocimientos.

En el siguiente artículo, titulado "Educación, infancia y género: una radiografía política de la situación en España”, de Magdalena Jiménez Ramírez, se presenta una discusión sobre las políticas y los aspectos sociales de la infancia en España. Se analiza, asimismo, la problemática asociada a la escasez de políticas sociales al cuidado de la infancia y las estrategias utilizadas por las madres para hacer compatible el trabajo de madre con el trabajo profesional. La revisión de este documento dejará al lector con un panorama más amplio de lo que sucede cuando se combina la necesidad de atención de un sector de la población infantil con una casi completa imposibilidad para atender a esta demanda. Es muy probable que el lector, después de todo, se quede con la idea de que las problemáticas en torno a la población infantil en España descritas en este documento no nos son tan ajenas. Asimismo, es probable también que el lector identifique cómo las estrategias empleadas por las madres españolas para compaginar su vida profesional con su labor de madre tienen mucha similitud también con las estrategias que emplean las madres mexicanas. La autora finaliza este documento con una reflexión acerca de cómo la atención a las desigualdades sociales debe comenzar desde la atención en las primeras etapas de la vida.

De igual manera, la revista nos presenta una situación que tampoco nos es ajena en el artículo siguiente, "Jóvenes ante un futuro sin futuro: importancia de la educación en valores como propuesta de desarrollo personal y social del colectivo juvenil", de Enrique García Jiménez y Rocío Lorente García. El artículo habla de cómo los jóvenes ninis, marginados, excluidos, miembros de las generaciones perdidas o mileuristas (término para referirse a quienes no ganan más de mil euros mensuales... jallá en Europa por supuesto!) son "jóvenes que sienten un rechazo tanto a estudiar como a trabajar..." Estos jóvenes, en voz de los autores, "han perdido la ilusión y la 
fuerza por las distintas conquistas sociales... mostrándose apáticos y acomodaticios, sin buscar responsabilidades, viviendo únicamente el presente desde el ocio y el disfrute..." Es por ello que la educación debe tener la misión desde la enseñanza de los valores, de cambiar la mentalidad de estas generaciones ante un fracaso que es considerado, incluso, sistémico.

La última sección de la revista, llamada "Autores con trayectoria", presenta un artículo de Andrés Fábregas Puig, "La educación superior como vehículo para la articulación intercultural en América Latina", en donde de manera crítica se presenta un análisis de la función que históricamente se ha asignado a las universidades en América Latina y el papel que juegan actualmente las universidades multi e interculturales, así como los modelos que las originan. Dice Puig que nuestras universidades han sido "concebidas como instrumentos para la aculturación y la homogeneización de la población... fomentando y acrecentando un prejuicio contra la variedad cultural, a través de inculcar en la juventud la idea de que los conocimientos de los pueblos originarios eran inválidos...", así como sus lenguas, su cultura y tradiciones. Es necesario un nuevo modelo de universidad que contribuya a la formación de un nuevo ciudadano, que valore altamente la diversidad cultural y acepte la pluralidad. Ello va más allá de la tolerancia. Se trata de aceptar y de disfrutar la variedad de la cultura, la riqueza mayor de los países latinoamericanos. Nuestras sociedades están urgidas de pasar del solo multiculturalismo a la conformación de sociedades plurales con relaciones interculturales equitativas.

Si ponemos la revista Punto CuNorte en una perspectiva mucho más amplia, nos daremos cuenta que, en conjunto, se trata de un documento que nos ofrece una visión general acerca de diversos aspectos de la agenda educativa nacional e internacional. Nos ofrece un viaje desde las instituciones de educación superior interculturales y los retos que plantean la necesidad de nuevos modelos, hasta problemáticas emergentes como el papel de las nuevas tecnologías en los procesos que se dan en la escuela o la necesidad de intervenir desde la enseñanza de valores, en los problemas de actualidad que caracterizan a los sectores jóvenes de la población.

Es una publicación sumamente recomendable ${ }^{1} \mathrm{y}$ pieza indispensable para quien intentar encontrar más elementos que abonen al armado del complejo rompecabezas del estado actual de la educación y los retos que a mediano y largo plazo enfrenta.

1 El lector la puede encontrar de manera gratuita y completa en: http://puntocunorte.com/wp-content/ uploads/2015/06/1330-Punto-CUNorte-2-interiores-.pdf 